\title{
The full moon and motorcycle related mortality: population based double control study
}

\author{
Donald A Redelmeier, ${ }^{1}$ Eldar Shafir ${ }^{2}$
}

${ }^{1}$ Department of Medicine, University of Toronto, Canada;

Division of General Internal

Medicine, Sunnybrook Health

Sciences Centre, Toronto, ON

M4N 3M5, Canada

${ }^{2}$ Department of Psychology,

Princeton University, NJ, USA;

Woodrow Wilson School of

Public and International Affairs,

Princeton University, NJ, USA

Correspondence to:

D A Redelmeier

dar@ices.on.ca

Cite this as: BMJ 2017;359:j5367 http://dx.doi.org/10.1136/bmj.j5367

Accepted: 1 November 2017

\author{
ABSTRACT \\ OBJECTIVE \\ To test whether a full moon contributes to motorcycle \\ related deaths.
}

\section{DESIGN}

Population based, individual level, double control, cross sectional analysis.

SETTING

Nighttime (4 pm to $8 \mathrm{am}$ ), United States.

PARTICIPANTS

13029 motorcycle fatalities throughout the United

States, 1975 to 2014 (40 years).

MAIN OUTCOME MEASURE

Motorcycle fatalities during a full moon.

\section{RESULTS}

13029 motorcyclists were in fatal crashes during 1482 relevant nights. The typical motorcyclist was a middle aged man (mean age 32 years) riding a street motorcycle with a large engine in a rural location who experienced a head-on frontal impact and was not wearing a helmet. 4494 fatal crashes occurred on the 494 nights with a full moon (9.10/ night) and 8535 on the 988 control nights without a full moon (8.64/night). Comparisons yielded a relative risk of 1.05 associated with the full moon (95\% confidence interval 1.02 to $1.09, \mathrm{P}=0.005$ ), a conditional odds ratio of 1.26 (95\% confidence interval 1.17 to $1.37, \mathrm{P}<0.001$ ), and an absolute increase of 226 additional deaths over the study interval. The increase extended to diverse types of motorcyclists, vehicles, and crashes; was accentuated during a supermoon; and replicated in analyses from the United Kingdom, Canada, and Australia.

\section{WHAT IS ALREADY KNOWN ON THIS TOPIC}

Millions of Americans ride motorcycles, of whom thousands will have a life threatening crash each year

Fatal motorcycle crashes have increased in recent years and now account for one in seven total road traffic deaths in the United States

Momentary distraction is a common contributor to road traffic deaths and explains an unknown number of fatal motorcycle crashes

\section{WHAT THIS STUDY ADDS}

A modest absolute increased risk of a fatal motorcycle crash was associated with the full moon in the United States

The increased risk of death associated with the full moon further replicated in analyses from the United Kingdom, Canada, and Australia

The increased risk of death was not necessarily caused by distraction since a full moon might also lead to more riding, faster speeds, added traffic, or other changes

\section{CONCLUSION}

The full moon is associated with an increased risk of fatal motorcycle crashes, although potential confounders cannot be excluded. An awareness of the risk might encourage motorcyclists to ride with extra care during a full moon and, more generally, to appreciate the power of seemingly minor distractions at all times.

\section{Introduction}

Motorcycle crashes are a common cause of mortality worldwide, resulting in more than 100000 fatalities in America since $1975 .^{1-3}$ Motorcycle crashes in the United States account for nearly 5000 deaths annually, amounting to about one in seven road traffic fatalities and $\$ 6.0 \mathrm{bn}$ ( $€ 4.5 \mathrm{bn}$; $€ 5.1 \mathrm{bn}$ ) to $\$ 12 \mathrm{bn}$ in societal costs. ${ }^{4}$ The average motorcyclist in the US faces a greater risk of death than a drunk driver with no seatbelt traveling the same distance. ${ }^{56}$ Unlike the case with other vehicles, few advances in engineering and enforcement in recent years have been effective at reducing motorcycle related fatalities. ${ }^{7-9}$ For millions of adults, riding a motorcycle may be perhaps the single most dangerous behavior engaged in on a regular basis. ${ }^{10}$

A full moon occurs about 12 times a year and has been a source of fascination since antiquity. ${ }^{11}$ It grabs people's attention, has been the subject of popular books and songs (ranging from "After the Gold Rush" by Neil Young to "Amazing" by Kanye West), is the topic of legends and myths worldwide, and is a frequent image in advertising campaigns. ${ }^{12-16}$ We hypothesized that because people's attention is naturally drawn to a full moon, it might contribute to fatal motorcycle crashes. ${ }^{17}$ In particular, glancing at a full moon takes the motorcyclist's gaze off the road, which could result in a loss of control. ${ }^{18} \mathrm{~A}$ full moon might also lead to changes in surrounding traffic behaviors, such as distracting other motorists or pedestrians from noticing an oncoming motorcycle. ${ }^{19}$

For safe motorcycling, riders need to orient their attention, ignore distractions, and continuously monitor the dynamic surroundings. Research on perception distinguishes between goal directed attention and stimulus driven attention, the latter denoting moments where attention is temporarily diverted by an extraneous object. ${ }^{2021}$ The three features most likely to attract stimulus driven attention are large size, bright luminance, and abrupt onset, ${ }^{22-24}$ all of which the full moon possesses (including occasional abrupt onset when the full moon suddenly appears after being occluded). To test for potential distraction, we analyzed the largest database available in the US with the most rigorous safety data to ascertain whether a full moon might contribute to fatal motorcycle crashes. 


\section{Methods \\ Study setting}

We obtained population based individual level road safety data for the United States from the National Highway Traffic Safety Administration. These data were accrued from the Fatality Analysis Reporting System, the official registry of fatal crashes involving a motor vehicle traveling on public roads in the United States. ${ }^{25}$ The database is freely available, has been validated in past research, is subjected to ongoing scrutiny, and exceeds a million total deaths. ${ }^{26}$ The database encompasses only fatal crashes and has limitations owing to a lack of data on driver education, training, speed, direction, congestion, and travel distances. We included all available years from the database's inception to 2014, with no exclusions (1 January 1975 to 31 December 2014; 494 full moons).

\section{Selection criteria}

We focused on all fatal motorcycle crashes in the Fatality Analysis Reporting System. The specific database codes evolved over time and we identified the vehicle type for each calendar year (code 15 for 1975-81, code 20 for 1982-90, and code 80 for 1991-2014). This definition included street, off-road, or other motorcycle styles and excluded bicycles, scooters, snowmobiles, wheelchairs, skateboards, and all-terrain vehicles. ${ }^{27}$ The Fatality Analysis Reporting System provided further data characterizing the motorcyclist (age, sex, seating position, helmet use), vehicle (style, vintage, engine size), environment (location, century, season, weekday), and crash (vehicle count, impact location, object mobility).

\section{Full moon nights}

We defined the full moon as the one night each month when the entire facing surface was illuminated, as viewed from Earth. On rare occasions, a month had two full moons; in such cases we included both appearances (eg, 2 January 1999 and 31 January 1999). We defined nighttime as the interval between $4 \mathrm{pm}$ and 8 am (16 hours) to include all hours when the full moon might be visible over the continental US (including relevant hours of dusk and dawn). The remaining interval between 8 am and 4 pm (eight hours) was defined as daytime and excluded from analysis (retained for secondary analysis). Fatalities with missing crash times $(<1 \%)$ were coded as nighttime (analyses excluding these deaths yielded slightly larger effect sizes and are not reported).

We obtained dates of a full moon from dateandtime. com, identified as the widely cited source referenced by scientific and mainstream media. ${ }^{28}$ Each full moon was further classified as a supermoon or not, depending on whether alignment coincided near to the time of closest orbital approach. ${ }^{29}$ The term supermoon was coined only recently, yet astronomical calculators at dateandtime.com were used to determine such occurrences retrospectively with no missing data. The distance between Earth and Moon is about 50000 $\mathrm{km}$ closer at perigee than apogee, equal to about a
$13 \%$ shorter distance and 30\% increased brightness during a supermoon. ${ }^{30}$ The databases contained no information on local weather or cloud cover (thereby potentially biasing estimates to the null).

\section{Control nights}

We defined controls as the exact night one week before and one week after the full moon; for example, the full moon on Sunday 31 January 1999 was matched to control dates of Sunday 24 January 1999 and Sunday 7 February 1999. This matching ensured identical time intervals for all comparisons and directly controlled for weekday, seasonal, and yearly trends. Doing so also indirectly reduced confounding from differences in training of the motorcyclists, traffic enforcement, individual personality, road design, vehicle condition, healthcare access, and many other influences on crash deaths. ${ }^{31}$ Validation of this approach appears elsewhere in analyses of road traffic risks surrounding large societal events. ${ }^{32-34}$

\section{Statistical analysis}

For the primary analysis we used a binomial test to evaluate the average number of fatal motorcycle crashes on full moon nights compared with control nights. Stratified analyses accounted for characteristics of the motorcyclist, vehicle, environment, and crash. All P values were two tailed, with relative risk estimates calculated using exact 95\% confidence intervals. Hierarchical analyses that preserved the pair matching between each full moon and corresponding control nights yielded larger effects and are reported as conditional odds ratios. ${ }^{35}$ Sensitivity analyses that additionally included the night immediately before and after a full moon yielded a greater number of excess deaths associated with a full moon with a marginally attenuated relative risk estimate and are not reported.

\section{Further replication}

We repeated our analyses in three additional countries, with study protocols receiving approvals from the ethics board of the Sunnybrook Health Sciences Centre and corresponding agencies in each country as needed. We chose the United Kingdom, Canada, and Australia because each is similar to the United States in language, culture, demographics, healthcare, and technology. ${ }^{36}$ National traffic agencies provided available data for each country. ${ }^{37-39}$ Clock times were based on local hours for each time zone. The aggregated database included the United Kingdom (1 January 1986 to 31 December 2010, 309 full moons), Canada (1 January 1999 to 31 December 2014, 198 full moons), and Australia (1 January 1989 to 31 December 2013, 309 full moons).

\section{Patient involvement}

No patients were involved in setting the research question or the outcome measures, nor were they involved in developing plans for recruitment, design, or implementation of the study. No patients were 
asked to advise on interpretation or writing up of results. There are no prespecified plans to disseminate the results of the research to study participants or the relevant patient community.

\section{Results}

\section{Descriptive overview}

A total of 13029 people were in a fatal motorcycle crash during the 1482 separate nights in the United States (494 full moon nights, 988 control nights). The typical motorcyclist was a middle aged man riding a street bike

\begin{tabular}{|c|c|c|}
\hline \multirow[b]{2}{*}{ Characteristics } & \multicolumn{2}{|l|}{ No (\%) } \\
\hline & Full moon night $(n=4494)$ & Control night $(n=8535)$ \\
\hline \multicolumn{3}{|l|}{ Age (years): } \\
\hline$\leq 29$ & $2482(55)$ & $4666(55)$ \\
\hline$\geq 30$ & $2012(45)$ & $3869(45)$ \\
\hline \multicolumn{3}{|l|}{ Sex: } \\
\hline Men & 3981 (89) & $7541(88)$ \\
\hline Women & $513(11)$ & $994(12)$ \\
\hline \multicolumn{3}{|l|}{ Seating position: } \\
\hline Driver & $3983(89)$ & $7572(89)$ \\
\hline Other & $511(11)$ & $963(11)$ \\
\hline \multicolumn{3}{|l|}{ Helmet protection: } \\
\hline Yes & $1828(41)$ & $3386(40)$ \\
\hline No & $2666(59)$ & $5149(60)$ \\
\hline \multicolumn{3}{|l|}{ Engine displacement: } \\
\hline$\geq 500 \mathrm{cc}$ & $4154(92)$ & $7890(92)$ \\
\hline$\leq 499$ cc or missing & $340(8)$ & $645(8)$ \\
\hline \multicolumn{3}{|l|}{ Motorcycle style: } \\
\hline Street & $3080(69)$ & $5831(68)$ \\
\hline Other & $1414(31)$ & $2704(32)$ \\
\hline \multicolumn{3}{|c|}{ Motorcycle vintage (years): } \\
\hline$\geq 3$ & $3036(68)$ & $5727(67)$ \\
\hline$\leq 2$ & $1458(32)$ & $2808(33)$ \\
\hline \multicolumn{3}{|l|}{ Region of crash: } \\
\hline Northeast & $681(15)$ & $1263(15)$ \\
\hline South & $1656(37)$ & $3177(37)$ \\
\hline Midwest & $1076(24)$ & $2021(24)$ \\
\hline West & $1081(24)$ & $2074(24)$ \\
\hline \multicolumn{3}{|l|}{ Location: } \\
\hline Urban & $1473(33)$ & $2889(34)$ \\
\hline Rural & $2143(48)$ & $4016(47)$ \\
\hline Unclassified & $878(20)$ & $1630(19)$ \\
\hline \multicolumn{3}{|l|}{ Period: } \\
\hline $1975-99$ & $2846(63)$ & $5384(63)$ \\
\hline $2000-14$ & $1648(37)$ & $3151(37)$ \\
\hline \multicolumn{3}{|l|}{ Season: } \\
\hline Spring-summer & $3077(68)$ & $5910(69)$ \\
\hline Autumn-winter & $1417(32)$ & $2625(31)$ \\
\hline \multicolumn{3}{|l|}{ Day of week: } \\
\hline Weekend & $1940(43)$ & $3639(43)$ \\
\hline Weekday & $2554(57)$ & $4896(57)$ \\
\hline \multicolumn{3}{|l|}{ Nighttime period: } \\
\hline $4 \mathrm{pm}-1159 \mathrm{pm}$ & $3294(73)$ & $6158(72)$ \\
\hline $12 \mathrm{pm}-8 \mathrm{am}$ & $1200(27)$ & $2377(28)$ \\
\hline \multicolumn{3}{|l|}{ Location of impact: } \\
\hline Frontal & $3004(67)$ & $5698(67)$ \\
\hline Other & $1490(33)$ & $2837(33)$ \\
\hline \multicolumn{3}{|l|}{ Dynamics of collision: } \\
\hline Stationary object & $2220(49)$ & $4345(51)$ \\
\hline Moveable object & $2274(51)$ & $4190(49)$ \\
\hline \multicolumn{3}{|l|}{ Vehicles involved: } \\
\hline Single & $2037(45)$ & $4013(47)$ \\
\hline Multiple & $2457(55)$ & $4522(53)$ \\
\hline
\end{tabular}

with a large engine in a rural location who experienced a head-on frontal impact (table 1). Less than half were wearing a helmet. The distribution of characteristics was similar between fatal crashes on full moon nights and on control nights. All mean characteristics for the two groups were within $2 \%$ of each other, and no individual difference was statistically significant. Most crashes (73\%) occurred during the hours before midnight and the remainder (27\%) during the hours after midnight.

\section{Primary analysis}

Overall, 4494 fatal crashes occurred on the 494 nights with a full moon, equal to 9.10 per night, and 8535 on the 988 control nights without a full moon, equal to 8.64 per night. Comparisons between the two groups yielded a relative risk of 1.05 associated with the full moon (95\% confidence interval 1.02 to $1.09, \mathrm{P}=0.005$ ), a conditional odds ratio of 1.26 (95\% confidence interval 1.17 to $1.37, \mathrm{P}<0.001$ ), and an absolute total increase of 226 additional fatal motorcycle crashes over the study period (fig 1). The average increase in risk amounted to one additional fatal crash associated with two full moon nights.

\section{Tests of robustness}

The relative increase in risk associated with a full moon was consistent for crashes with diverse characteristics. A nominal increased risk extended to different locations, decades, seasons, weekdays, and crash characteristics (fig 2). The increase was apparent regardless of the motorcyclists age, sex, seating position, and helmet use (fig 3). Similarly, the increase was apparent for different motorcycle styles, vintages, and engine sizes. All subgroups overlapped the main analysis, none showed a contrary trend, and each subgroup with at least 5000 controls was statistically significant in isolation. The relative increase in risk was generally accentuated in rural locations and attenuated in urban locations.

\section{Daylight controls}

Secondary analyses evaluated crash risks during daytime hours on the same dates (to check for a lack of an association where no association was anticipated). The daytime hours on the 494 full moon dates accounted for 1509 fatal crashes, equal to 3.05 per day. The daytime hours on the 988 control dates accounted for 3178 fatal crashes, equal to 3.22 per day. Comparisons between the two groups yielded a relative risk of 0.95 (95\% confidence interval 0.89 to 1.01 , $\mathrm{P}=0.098)$. The absolute difference between daytime hours on full moon dates compared with control dates totaled 80 fewer people in fatal motorcycle crashes over the study interval.

\section{Supermoon nights}

A further analysis classified the 494 full moon nights as either a supermoon night or a full moon night, depending on whether alignment coincided with the time of closest orbital approach. Overall, 703 fatal 


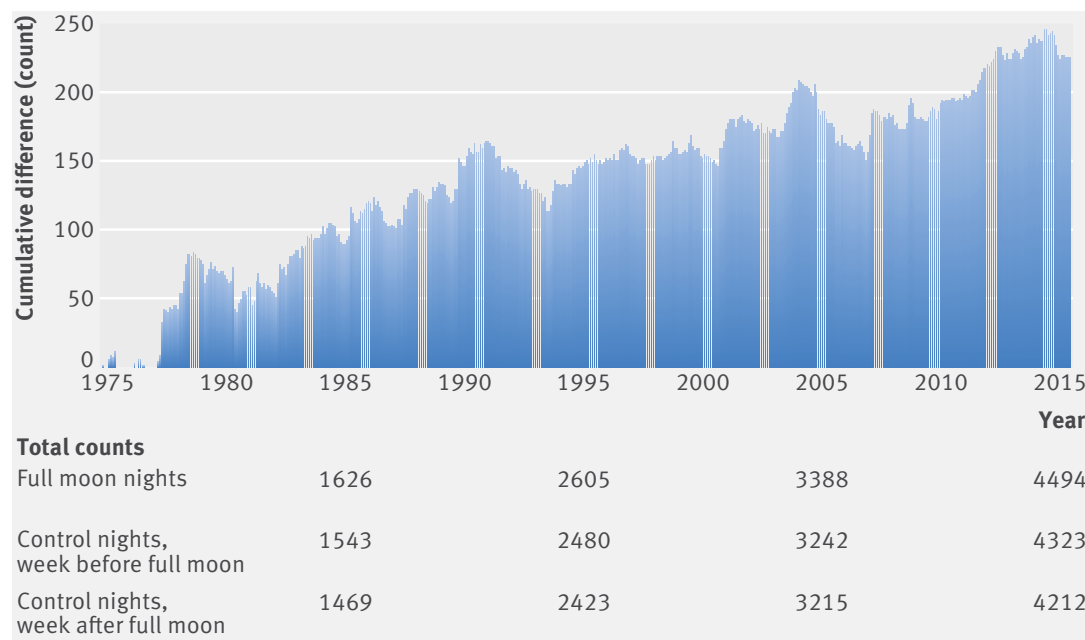

Fig 1 | Cumulative count of excess fatalities on full moon nights compared with control nights

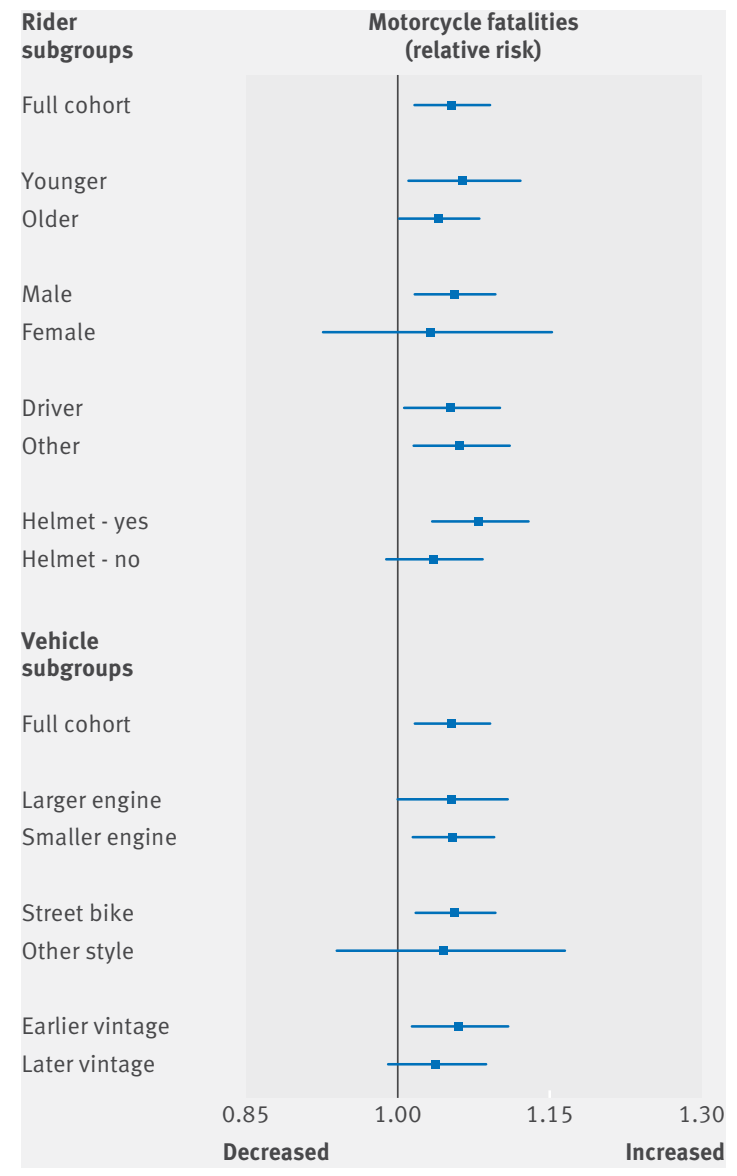

Fig 3 | Relative risk of a motorcycle fatality on full moon nights by characteristics of motorcyclist and vehicle

crashes occurred on the 65 supermoon nights (with increased brightness and larger apparent size), equal to 10.82 per night, and 3791 on the 429 regular full moon nights, equal to 8.84 per night. Analyses yielded a relative risk during a supermoon compared with regular full moon of 1.22 (95\% confidence interval 1.13 to $1.33, \mathrm{P}<0.001)$. Restricting analyses to the 65 supermoon nights and 130 corresponding control nights yielded a relative risk of 1.32 (1.20 to 1.45 , $\mathrm{P}<0.001)$.

\section{Consistency between control nights}

In secondary analysis we compared the control night one week before a full moon night with the control night one week after a full moon night. On those nights, we reasoned, the moon was partially illuminated and visible at different hours. Specifically, a partial moon one week before a full moon is mostly seen before midnight (hidden otherwise), whereas a partial moon one week after a full moon is mostly seen after midnight (hidden otherwise). Because motorcycle crashes predominate during hours before midnight, we predicted more fatal crashes on control nights one week before a full moon than on control nights one week after a full moon. Overall, 4323 fatal crashes occurred on 494 control nights one week before a full moon and 4212 on 494 control nights after a full
Fig 2 | Relative risk of a motorcycle fatality on full moon nights by location, time, and type of crash 


\begin{tabular}{|c|c|c|c|}
\hline Countries & Full moon nights & Total motorcycle fatalities* & Relative risk $(95 \% \mathrm{Cl})$ \\
\hline United States & 494 & 13029 & 1.05 (1.02 to 1.09$)$ \\
\hline United Kingdom & 309 & 1414 & $1.06(0.95$ to 1.18$)$ \\
\hline Canada & 198 & 209 & $1.12(0.85$ to 1.49$)$ \\
\hline Australia & 309 & 380 & $1.11(0.91$ to 1.38$)$ \\
\hline Combined & -- & 15032 & 1.06 (1.02 to 1.09$)$ \\
\hline
\end{tabular}

moon, yielding a conditional odds ratio of 1.12 (95\% confidence interval 1.02 to $1.22, \mathrm{P}=0.01$ ).

International analysis

A total of 2003 additional people were in fatal motorcycle crashes in the United Kingdom, Canada, and Australia during the full moon night and the control nights. The aggregated data yielded 701 fatal crashes on full moon nights, equal to 2.58 per night, and 1302 fatal crashes on control nights, equal to 2.39 per night. Comparisons between the two groups yielded a relative risk during the full moon of 1.08 (95\% confidence interval 0.98 to 1.18). Examination of each country separately yielded an increase for each (range 1.06-1.12 fatal crashes per night) that overlapped the American estimate (table 2). Although these comparisons based on smaller samples were not statistically significant using simple binomial count statistics, all were consistent with the American data.

\section{Discussion}

In this study of motorcycle related deaths in the United States over four decades we found that such deaths were more common at night, particularly during a full moon. The relative effect size associated with the full moon is small and only important because of the large number of people repeatedly exposed. Although others may have alternative interpretations because observational analyses cannot exclude the possibility of hidden confounding, we believe the findings are not easily explained as artifacts attributable to selection bias, ascertainment bias, reverse causality, fluctuating weather, subjective reporting, or random chance. ${ }^{40-44}$ The findings are also difficult to attribute to confirmation bias, self fulfilling prophecies, social reinforcement, paranormal phenomenon, or geophysical effects. ${ }^{45-49}$

Several aspects of attention and perception could explain an association between the full moon and motorcycle fatalities. A full moon is infrequent and spectacular, thereby creating a natural distraction. ${ }^{50}$ The full moon is large and bright against a dark sky, and thus provides a striking contrast of luminance. It can appear abruptly to a motorcyclist, such as when riding around buildings, through turns, past trees, and over hills. A full moon also creates optical illusions that engender wonderment and tends to rise above the horizon in the night hours exactly at the time motorcycle crashes generally predominate. ${ }^{51}$ Beyond these, a full moon might contribute to increased outdoor activity of all types, including more frequent travel, faster speeds, longer distances, unfamiliar routes, added cross traffic, and mixtures of less experienced travelers.

\section{Limitations of this study}

Our study has many limitations. We did not analyze automobiles, which have a wider stable base than motorcycles, extensive protection of occupants, and engineering elements such as airbags that mitigate the risk of death associated with momentary distraction. ${ }^{52}$ We did not explore more complex Fourier statistical models of intermediate lunar phases and positions during other nights (including the new moon). ${ }^{53}$ We tested only one source of inattention whereas a motorcyclist can encounter many other distractions and traffic hazards. The shared nature of road traffic means crashes often involve other road users who also have differing reasons for travel. ${ }^{54}$ Furthermore, the consistent increased risk of death for diverse subgroups does not prove all motorcyclists are equally vulnerable because the observed confidence intervals were always wide.

An additional limitation concerns the interpretation of the magnitude of the observed association. An average motorcyclist probably spends only a small fraction of time gazing at a full moon. As a consequence, a net increase in fatal crashes associated with the full moon should show only a modest magnitude since a large increased risk would be implausible after a transient exposure. ${ }^{55}$ Moreover, a full moon is inert, distant, and familiar so the combined effects of many other roadway distractions may be much larger. ${ }^{56} \mathrm{~A}$ comprehensive understanding of crash risk is also problematic since a $5 \%$ increase in travel distances is unlikely to explain this degree of risk, whereas a 5\% increase in travel speeds could easily account for an association of this magnitude. ${ }^{57} 58$

Several other limitations merit emphasis because large scale databases lack clinical details and motorcyclists are sometimes non-conformist outliers. The extent of cloud cover, prevailing weather, and moon visibility were unknown in our study. Finer analyses of the exact start and end of night were not feasible to account for the geographic latitude of the crash site. Similarly, analyses of the exact interval of moon rise and moon set were not feasible to account for time zone longitude. The speed and direction of the motorcycle at impact were also uncertain. In addition, fallible data entry in government databases can introduce an unknown number of spurious errors. These imprecisions add extraneous observations that generally bias all comparisons to the null.

A further finding in our study was that the increased relative risk of a fatal motorcycle crash was accentuated under a supermoon. The absolute increased risk was substantial and amounted to about two additional deaths on a night with a supermoon. To the best of our knowledge, this increased risk has not been previously mentioned, even in myths around the supermoon. The observed correlation between a purely visual event and an increase in fatalities supports the theory that momentary distraction is a contributing mechanism. ${ }^{59}$ 
An alternative explanation is that a supermoon enhances the lighting of surrounding landscapes that may lead motorcyclists to misjudge distance and speed (analogous to the aerial perspective optical illusion experienced by aviators and mountaineers in sunlight). ${ }^{60-63}$

\section{Conclusion}

Our study suggests that extra care is needed when riding a motorcycle during a full moon. More broadly, the findings highlight the importance of constant attention when riding and could serve as a conversation starter for clinicians who care for patients who motorcycle (currently eight million in America, including survivors of cancer). ${ }^{64-66}$ Standard safety recommendations to avoid a crash might include maximizing visibility, wearing protective clothing, and maintaining the vehicle in excellent condition. ${ }^{67-69}$ Additional strategies while riding might include wearing a helmet, activating headlights, scanning the road surface for defects, respecting the weather, being wary of left turning vehicles, obeying traffic laws, and forgoing stunts. ${ }^{70} 71$ Although a momentary distraction might be difficult to avoid, attention can be immediately redirected by a cognizant motorcyclist. ${ }^{14}$

We thank the following for helpful comments: Bryn Bandt-Law, Junaid Bhatti, Alex Kopp, Fizza Manzoor, Sheharyar Raza, Lee Ross, Robert Tibshirani, Jason Woodfine, and Christopher Yarnell.

Contributors: DAR wrote the first draft of the manuscript. Both authors contributed to the study design, manuscript preparation, data analysis, results interpretation, critical revisions, and final decision to submit. DAR had full access to all the data in the study, takes responsibility for the integrity of the data, and is accountable for the accuracy of the analysis. DAR is the guarantor.

Funding: This project was supported by a Canada research chair in medical decision sciences, the Canadian Institute for Advanced Research, the Canadian Institutes of Health Research, and the Ontario Ministry of Transportation. The views are those of the authors and do not necessarily reflect the Ontario Ministry of Health.

Competing interests: All authors have completed the ICMJE uniform disclosure form at www.icmje.org/coi disclosure.pdf and declare: no support from any organization for the submitted work; no financial relationships with any organizations that might have an interest in the submitted work in the previous three years; no other relationships or activities that could appear to have influenced the submitted work.

Ethical approval: The study protocol was approved by the research ethics board of Sunnybrook Health Sciences Center, including a waiver for direct patient consent. All data are available through the National Highway Traffic Safety Agency.

Data sharing: No additional data are available. Original data are available at the National Highway Traffic Safety Administration Fatality Analysis Reporting System (www-fars.nhtsa.dot.gov/Main/index. aspx/)

Transparency: The lead author (DAR) is the manuscript's guarantor and affirms the manuscript is an honest, accurate, and transparent account of the study being reported; that no important aspects of the study have been omitted; and that any discrepancies from the study as planned have been explained.

This is an Open Access article distributed in accordance with the Creative Commons Attribution Non Commercial (CC BY-NC 4.0) license, which permits others to distribute, remix, adapt, build upon this work non-commercially, and license their derivative works on different terms, provided the original work is properly cited and the use is non-commercial. See: http://creativecommons.org/licenses/ by-nc/4.0/

1 World Health Organization. World report on road traffic injury prevention. Geneva: WHO. 2013. www.who.int/violence_injury_ prevention/publications/road_traffic/world_report/en/. Accessed on 14 June 2016.
2 Busko A, Hubbard Z, Zakrison T. Motorcycle-Helmet Laws and Public Health. N Engl J Med 2017;376:1208-9. doi:10.1056/ NEJMp1615621

3 US Department of Transportation. Traffic Safety Facts. www.nhtsa. gov/. Accessed on 14 December 2016

4 National Highway Traffic Safety Administration. Costs of injuries resulting from motorcycle crashes: A literature review. US Department of Transportation, 2002. [DOT HS 809 242]

5 National Vital Statistics Reports. Deaths: Preliminary data for 2011. Washington: Centres for Disease Control 2012 [Vol 61, No 6] www. cdc.gov/nchs/data/nvsr/nvsr61/nvsr61_06.pdf

6 Evans L. Traffic safety. Science Serving Society, 2004.

7 National Highway Traffic Safety Administration. Traffic safety facts: motorcycles. Washington: US Department of Transportation 2002 [DOT HS 812 035] www-nrd.nhtsa.dot.gov/Pubs/812035.pdf

8 Retting R, Rothenberg H. Motorcycle Traffic Fatalities by State: 2015 Preliminary Data. Washington: Govenors Highway Traffic Association, 2017. www.ghsa.org/sites/default/files/2016-12/ motorcycles 2015.pdf

9 Gulland A. Global deaths from road incidents plateau. BMJ 2015;351:h5565. doi:10.1136/bmj.h5565

10 McCarthy M. US has worst traffic accident death rate among high income countries. BMJ 2016;354:i3799. doi:10.1136/bmj.i3799

11 Sarton G. Lunar influences on living things. Isis 1939;30:495-507. doi:10.1086/347530.

12 Nudd T. Crescent Moon Becomes the Lime in the Bottle on Heavenly Corona Billboard in NYC: Stop by for a look this weekend. 13 June 2013. www.adweek.com/adfreak/crescent-moon-becomes-limebottle-heavenly-corona-billboard-nyc-150273

13 Myths encyclopedia: myths and legends of the world. Moon. www. mythencyclopedia.com/Mi-Ni/Moon.html\#ixzz3pPLJq083

14 Burns W. Corona shoots the moon (literally) in latest advertising effort. 14 June 2013. www.forbes.com/sites/willburns/2013/06/14/ corona-shoots-the-moon-literally-in-latest-advertising-effort/

15 Coffee P. The Häagen-Dazs 'Ice Moon’ Demands Your Attention. 4 Oct 2012 www.adweek.com/prnewser/haagen-dazs-ice-moonawesome/47707

16 AT\&T. Up\&Up. www.youtube.com/watch?v=1wgPBHd8NzE

17 Schweizer TA, Kan K, Hung Y, Tam F, Naglie G, Graham SJ. Brain activity during driving with distraction: an immersive fMRI study. Front Hum Neurosci 2013;7:53. doi:10.3389/fnhum.2013.00053

18 Klauer SG, Guo F, Simons-Morton BG, Ouimet MC, Lee SE, Dingus TA. Distracted driving and risk of road crashes among novice and experienced drivers. N Engl J Med 2014;370:54-9. doi:10.1056/ NEJMsa1204142

19 Smith AP. A UK survey of driving behaviour, fatigue, risk taking and road traffic accidents. BMJ Open 2016;6:e011461. doi:10.1136/ bmjopen-2016-011461

20 Yantis S, Hillstrom AP Stimulus-driven attentional capture: evidence from equiluminant visual objects. J Exp Psychol Hum Percept Perform 1994;20:95-107. doi:10.1037/0096-1523.20.1.95

21 Irwin DE, Colcombe AM, Kramer AF, Hahn S. Attentional and oculomotor capture by onset, luminance and color singletons. Vision Res 2000;40:1443-58. doi:10.1016/S0042-6989(00)00030-4

22 Jonides J, Irwin DE. Capturing attention. Cognition 1981;10:145-50. doi:10.1016/0010-0277(81)90038-X

23 Proulx MJ, Egeth HE. Biased competition and visual search: the role of luminance and size contrast. Psychol Res 2008;72:106-13. doi:10.1007/s00426-006-0077-z

24 Proulx MJ. Size matters: large objects capture attention in visual search. PLoS One 2010;5:e15293. doi:10.1371/journal.pone.0015293

25 Fatality Analysis Reporting System Encyclopedia. National Highway Traffic Safety Administration. www-fars.nhtsa.dot.gov/Main/index. aspx. Accessed 12 February 2016.

26 National Highway Traffic Safety Administration. Traffic Safety Facts 2012. www-nrd nhtsa dot gov/Pubs/812032.pdf. Accessed 12 February 2016.

27 National Highway Traffic Safety Administration. Fatality Analysis Reporting System (FARS): Analytic User's Manuel 1975-2013. wwwnrd.nhtsa.dot.gov/Pubs/812092.pdf. Accessed 12 February 2015

28 timeanddate.com. www.timeanddate.com/information/. Accessed 12 February 2016.

29 Nolle R. Supermoon. www.astropro.com/features/articles/ supermoon/. Accessed 12 February 2016.

30 National Aeronautics and Space Administration. Super Full Moon. http://science.nasa.gov/science-news/science-atnasa/2011/16mar_supermoon/. Accessed 12 February 2016.

31 Tanner JC. Effect of weather on traffic flow. Nature 1952;4290:107. doi:10.1038/169107a0.

32 Redelmeier DA, Stewart CL. Driving fatalities on Super Bowl Sunday. N Engl I Med 2003;348:368-9. doi:10.1056/ NEJM200301233480423

33 Redelmeier DA, Tibshirani RJ. Driving fatalities on US presidential election days. JAMA 2008;300:1518-20. doi:10.1001/ jama.300.13.1518 
34 Redelmeier DA, Yarnell CJ. Road crash fatalities on US income tax days. JAMA 2012:307:1486-8. doi:10.1001/jama.2012.450

35 Redelmeier DA, Tibshirani RJ. A simple method for analyzing matched designs with double controls: McNemar's test can be extended. J Clin Epidemiol 2017;81:51-55.e2. doi:10.1016/j. jclinepi.2016.08.006

36 Evans L. Traffic fatality reductions: United States compared with 25 other countries. Am J Public Health 2014;104:1501-7. doi:10.2105/ AJPH.2014.301922

37 Economic and Social Data Service. www.esds.ac.uk/findingData/ subjectResults.asp?gn $=33267$ \&subcat $=$ XXXV

38 Government of Canada. Transport Canada. National Collision Database Online. wwwapps2.tc.gc.ca/Saf-Sec-Sur/7/NCDB-BNDC/p. aspx?c=100-0-0\&l=en

39 http://statistics.infrastructure.gov.au/atsb/login do?guest=guest\&tableld=user/atsbguest/Road\%20Deaths\%20 by 20 State $\% 20$ and\%20Territory.txd

40 Sackett DL. Bias in analytic research. J Chronic Dis 1979;32:51-63. doi:10.1016/0021-9681(79)90012-2

41 Greenland S, Morgenstern H. Confounding in health research. Annu Rev Public Health 2001;22:189-212. doi:10.1146/annurev. publhealth.22.1.189

42 Hulley SB, Cummings SR, Browner WS, Grady DG, Newman TB. Designing Clinical Research. Lippincott Williams \& Wilkins, 2013.

43 Schafer JA, Varano SP, Jarvis JP, Cancino JM. Bad moon on the rise? Lunar cycles and incidents of crime. / Crim Justice 2010;38:359-67. doi:10.1016/j.jcrimjus.2010.04.003.

44 Smith MP, Standl M, Schulz H, Heinrich J. Physical activity, subjective sleep quality and time in bed do not vary by moon phase in German adolescents. J Sleep Res 2017;26:371-6. doi:10.1111/ jsr.12472

45 Bradley DA, Woodbury MA, Brier GW. Lunar synodical period and widespread precipitation. Science 1962;137:748-9. doi:10.1126/ science.137.3532.748

46 Shah GM. Lunar influence on atmospheric ozone. Nature 1972:237:275. doi:10.1038/237275a0.

47 Balling RCJr, Cerveny RS. Influence of lunar phase on daily global temperatures. Science 1995;267:1481-3. doi:10.1126/ science.267.5203.1481

48 Fernández-Duque E, de la Iglesia H, Erkert HG. Moonstruck primates: owl monkeys (Aotus) need moonlight for nocturnal activity in their natural environment. PLoS One 2010;5:e12572. doi:10.1371/ journal.pone.0012572

49 Kohyama T, Wallace JM. Rainfall variations induced by the lunar gravitational atmospheric tide and their implications for the relationship between tropical rainfall and humidity. Geophys Res Lett 2016;43:918-23. doi:10.1002/2015GL067342.

50 Wilson FA, Stimpson JP. Trends in fatalities from distracted driving in the United States, 1999 to 2008. Am J Public Health 2010;100:2213-9. doi:10.2105/AJPH.2009.187179

51 Hershenson M. The moon illusion. Lawrence Erlbaum Associates, 1989

52 Alonso Y. Geophysical variables and behavior: LXXII. Barometric pressure, lunar cycle, and traffic accidents. Percept Mot Skills 1993;77:371-6. doi:10.2466/pms.1993.77.2.371

53 Riotte-Lambert L, Benhamou S, Chamaillé-Jammes S. Periodicity analysis of movement recursions. J Theor Biol 2013;317:238-43. doi:10.1016/j.jtbi.2012.10.026
54 Redelmeier DA, Yarnell CJ. Lethal misconceptions: interpretation and bias in studies of traffic deaths. J Clin Epidemiol 2012;65:467-73. doi:10.1016/j.jclinepi.2011.09.007

55 Redelmeier DA, Tibshirani RJ. Interpretation and bias in casecrossover studies. J Clin Epidemiol 1997;50:1281-7. doi:10.1016/ S0895-4356(97)00196-0

56 Klauer SG, Guo F, Simons-Morton BG, Ouimet MC, Lee SE, Dingus TA Distracted driving and risk of road crashes among novice and experienced drivers. N Engl J Med 2014;370:54-9. doi:10.1056/ NEJMsa1204142

57 Redelmeier DA, Bayoumi AM. Time lost by driving fast in the United States Med Decis Making 2010;30:E12-9. doi:10.1177/0272989X09357476

58 Redelmeier DA. The fallacy of interpreting deaths and driving distances. Med Decis Making 2014;34:940-3. doi:10.1177/ 0272989X14526642

59 Galéra C, Orriols L, M'Bailara K. Mind wandering and driving: responsibility case-control study. BMJ 2012;345:e8105. doi:10.1136/bmj.e8105

60 Leibowitz HW, Owens DA. Nighttime driving accidents and selective visual degradation. Science 1977;197:422-3. doi:10.1126/ science.197.4302.422-a

61 Liu BS. Association of intersection approach speed with drive characteristics, vehicle type and traffic conditions comparing urban and suburban areas. Accid Anal Prev 2007;39:216-23. doi:10.1016/j.aap.2006.07.005

62 Cheung B. Spatial disorientation: more than just illusion. Aviat Space Environ Med 2013;84:1211-4. doi:10.3357/ASEM.3657.2013

63 Redelmeier DA, Raza S. Life-threatening motor vehicle crashes in bright sunlight. Medicine (Baltimore) 2017;96:e5710. doi:10.1097/ MD.0000000000005710

64 Dunn J, Campbell M, Penn D, Dwyer M, Chambers SK. Amazon heart: an exploration of the role of challenge events in personal growth after breast cancer. J Psychosoc Oncol 2009;27:119-35. doi:10.1080/07347330802616084

65 Morris BA, Chambers SK, Campbell M, Dwyer M, Dunn J. Motorcycles and breast cancer: the influence of peer support and challenge on distress and posttraumatic growth. Support Care Cancer 2012;20:1849-58. doi:10.1007/s00520-011-1287-5

66 Muratore S, Hawes L, Farhat J, Reicks P, Gipson J, Beilman G. Riding into the golden years: injury patterns and outcomes of advanced-age motorcycle trauma. Am J Surg 2016;212:670-6. doi:10.1016/j. amjsurg.2016.06.011

67 Liu BC, Ivers R, Norton R, Boufous S, Blows S, Lo SK. Helmets for preventing injury in motorcycle riders. Cochrane Database Syst Rev 2008;(1):CD004333.

68 Lin MR, Kraus JF. A review of risk factors and patterns of motorcycle injuries. Accid Anal Prev 2009;41:710-22. doi:10.1016/j. aap.2009.03.010

69 Lastfogel J, Soleimani T, Flores R. Helmet use and injury patterns in motorcycle-related trauma. JAMA Surg 2016;151:88-90. doi:10.1001/jamasurg.2015.3225

70 Chisholm D, Naci H, Hyder AA, Tran NT, Peden M. Cost effectiveness of strategies to combat road traffic injuries in sub-Saharan Africa and South East Asia: mathematical modelling study. BMJ 2012;344:e612. doi:10.1136/bmj.e612

71 Simpson JC, Wilson S, Currey N. Motorcyclists' perceptions and experiences of riding and risk and their advice for safety. Traffic $/ n$ Prev 2015;16:159-67. doi:10.1080/15389588.2014.911852 